\title{
A Population-Based Study on Gestational Weight Gain according to Body Mass Index in the Southeast of Brazil
}

\author{
Ana Carolina Godoy, Simony Lira Nascimento, Karina Tamy Kasawara, \\ Nathalia Hatsue Oushiro, and Fernanda Garanhani Surita \\ Department of Obstetrics and Gynecology, University of Campinas (UNICAMP), Alexander Fleming 101, \\ 13083-881 Campinas, SP, Brazil \\ Correspondence should be addressed to Fernanda Garanhani Surita; surita@unicamp.br
}

Received 12 December 2013; Revised 7 May 2014; Accepted 8 May 2014; Published 25 May 2014

Academic Editor: Germán Vicente-Rodriguez

Copyright (C) 2014 Ana Carolina Godoy et al. This is an open access article distributed under the Creative Commons Attribution License, which permits unrestricted use, distribution, and reproduction in any medium, provided the original work is properly cited.

\begin{abstract}
Gestational weight gain (GWG) may interfere in perinatal outcomes and also cause future problems throughout woman's life. The aim of this population-based study is to evaluate the GWG in Campinas city, southeast of Brazil. A total of 1052 women, who delivered in the three major maternity hospitals in Campinas, were interviewed during postpartum period. The general average of GWG was $13.08 \pm 6.08$. Of total women, $13.6 \%$ were obese and $24.6 \%$ were overweight and, in these groups, $55.9 \%$ and $53.7 \%$, respectively, exceeded GWG according to the Institute of Medicine recommendations. $6.2 \%$ of total women had low body mass index (BMI) and 35.5\% in this group had insufficient GWG. Overweight and obese women had a higher risk of excessive GWG and delivery by c-section. The c-section rate was $58.9 \%$ and increased according to GWG. Prematurity was more prevalent first in obese and then in low BMI women. Considering the high BMI in women in reproductive age, it is necessary to take effective guidelines about lifestyle and nutritional orientation in order to help women reach adequate GWG. All of them could improve prenatal outcomes and women's heath as a whole.
\end{abstract}

\section{Introduction}

Obesity is considered as one of the major public health problems in the world and is considered as an epidemic in developed countries and low income countries. Every year at least 2.6 million of deaths by obesity and overweight occur. It is known that a person with obesity or overweight has higher risk of dyslipidemia, diabetes mellitus (DM), and hypertension [1,2]. In Brazil, the Health Ministry shows that $48 \%$ of women have higher weight than recommended. In São Paulo state it represents $48.6 \%$ of women with overweight [3].

During gestational period some women can exceed the weight gain recommended for pregnancy. It is estimated that $50 \%$ of women in infertility age are overweight or obese and $18 \%$ of women get pregnant with high body mass index (BMI), overweight, or obese [4]. According to World Health Organization (WHO) the prevalence of obesity during pregnancy is from $1.8 \%$ to $25.3 \%$. The obesity during pregnancy increases maternal-fetal morbidity and it is related to many complications due to high risk pregnancy and delivery outcomes [3]. In public health services in Brazil, the majority of pregnant women do not have the expected range recommended for weight gain during pregnancy [5-9].

Several maternal complications occur due to overweight and obesity, including gestational diabetes, pregnancy induced hypertension and preeclampsia, and high rates of c-section, all of them associated with longer hospitalization [10-15].

Pregnancy is a period in which women need a special care. Clinical trials have suggested a lifestyle change such as nutritional adequacy and physical activities programs to be adequate with the weight gain during pregnancy, prevention of excess weight gain, and weight retention in postpartum period [16-18]. Public health strategies involve gym classes as well as diet orientation during prenatal care which are important to support women to achieve the weight gain recommended during pregnancy and so avoid complications [18]. 
The aim of this study was to evaluate the gestational weight gain and this association with perinatal outcomes in one of the biggest cities in southeast of Brazil (Campinas city, São Paulo state).

\section{Materials and Methods}

A population-based study was approved by University of Campinas (UNICAMP) ethical committee (by the number 991/2011). Women were interviewed in immediate postpartum period in three major maternity hospitals in Campinas city, São Paulo, Brazil. According to health insurance each maternity hospital was as follows: public health service (Maternity A), private health service (Maternity B), and public and private health service (Maternity C). The data was assessed on immediate postpartum period, so every woman was at least primiparous.

The sample size was calculated in order to obtain a representative population of pregnant women in Campinas city, SP, Brazil. According to DATASUS/SISPRENATAL (Sistema de Acompanhamento do Programa de Humanização no PréNatal e Nascimento) database of 2010, birth rate of a single pregnancy by Campinas citizen was 14,693 . For sample size calculation the highest vulnerability possible was assumed based on the prevalence of delivery per year in Campinas, level of significance of 5\% and sampling error of 3\%, resulting $n=995$. There were three centers (maternities) including Maternity A (number of deliveries/year = 2002), Maternity B (number of deliveries/year $=1286$ ), and Maternity C (number of deliveries/year $=6800$ ), total of $n=12.423$ deliveries. Considering this total the three centers represent $16.1 \%$, $10.4 \%$, and $54.7 \%$, respectively.

The data collection was from November, 2011, to August, 2013. The inclusion criteria were as follows: women in immediate postpartum with live newborn and habitant in Campinas city. Women with multiple pregnancies, reading and communication difficulties, and any other condition that could interfere in the interview were excluded. Every woman included in this study signed a consent form. For data collection it was used a checklist to verify the inclusion criteria. The women included answered a questionnaire with socio-demographics and biometric characteristics.

The analysis of pregnancy weight gain was based on Institute of Medicine (IOM) recommendations, according to their previous BMI before pregnancy (women with low weight should gain between 12.2 and $18 \mathrm{~kg}$ during pregnancy, women with previous adequate weight should gain between 11 and $16 \mathrm{~kg}$, overweight women should gain between 7 and $11.5 \mathrm{~kg}$, and obesity women should gain between 5 and $9 \mathrm{~kg}$ [19]). Study participants showed that prepregnancy BMI was calculated based on participants' self-report of prepregnancy weight. Height and final weight were recorded from prenatal charts.

The adequacy of newborn weight to gestational age was evaluated according to Alexander scale and classified as adequate for gestational age (AGA), small for gestational age (SGA), and large for gestational age (LGA). Prematurity rate was defined based on gestational age and a newborn classified as $<37$ weeks was considered as preterm [20].
TABLE 1: Demographic characteristics and prepregnancy weight and BMI data of women in southeast of Brazil.

\begin{tabular}{|c|c|}
\hline Variables & $n=1052$ \\
\hline Age (years) - mean $\pm S D$ & $27.41 \pm 6.32$ \\
\hline$<19-n(\%)$ & $122(11.6)$ \\
\hline $20-34-n(\%)$ & $771(73.4)$ \\
\hline$>35-n(\%)$ & $158(15)$ \\
\hline \multicolumn{2}{|l|}{ Race $-n(\%)$} \\
\hline Caucasian & $519(49.5)$ \\
\hline Black/brown & $518(49.4)$ \\
\hline Others & $12(1.1)$ \\
\hline \multicolumn{2}{|l|}{ Educational attainment $-n(\%)^{*}$} \\
\hline Up to grade school & $225(21.5)$ \\
\hline Up to high school & $615(58.8)$ \\
\hline College university or advanced degree & $206(19.9)$ \\
\hline Married or common law $-n(\%)$ & $989(94.0)$ \\
\hline Planned pregnancy $-n(\%)$ & $524(49.8)$ \\
\hline \multicolumn{2}{|l|}{ Parity-n $(\%)$} \\
\hline 1 & $498(47.4)$ \\
\hline$\geq 2$ & $553(52.6)$ \\
\hline Gestational age at first prenatal visits-mean \pm SD & $12.03 \pm 5.97$ \\
\hline Number of prenatal visits-mean \pm SD & $8.73 \pm 2.37$ \\
\hline Prenatal at public health system $-n(\%)$ & $676(64.6)$ \\
\hline Smoking during pregnancy- $n(\%)$ & $85(8.1)$ \\
\hline Diabetes mellitus- $n(\%)$ & $62(5.9)$ \\
\hline Hypertension- $n(\%)$ & $92(8.8)$ \\
\hline Prepregnancy weight - mean \pm SD & $67.71 \pm 14.23$ \\
\hline Prepregnancy $\mathrm{BMI}^{* *}-$ mean $\pm \mathrm{SD}$ & $25.21 \pm 5.07$ \\
\hline $\mathrm{BMI}<18.5-n(\%)$ & $63(6.16)$ \\
\hline $\mathrm{BMI} \geq 18.5<25-n(\%)$ & $568(55.58)$ \\
\hline $\mathrm{BMI} \geq 25<30-n(\%)$ & $252(24.66)$ \\
\hline $\mathrm{BMI} \geq 30-n(\%)$ & $139(13.6)$ \\
\hline
\end{tabular}

BMI: body mass index; SD: standard deviation; ${ }^{*} 5$ missing data, ${ }^{* *} 29$ missing data.

The variables related to population characteristics, gestational weight gain, and adequacy of gestational weight gain according to BMI were described in absolute and relative frequency. Odds ratio (OR) was used with a confidence interval (CI) of 95\% to evaluate the excessive weight gain in accordance with their BMI. The significance level assumed was $5 \%$ and the statistical analysis was performed by program Epi-info version 5.1.

\section{Results}

A total of 1052 women were included: 238 (22.60\%) were from Maternity A, 217 (20.70\%) from Maternity B, and 597 (56.69\%) from Maternity C. The different percentages for the three hospitals included in the study were in accordance with the proportion of births by maternity in Campinas city in 2010.

Table 1 describes the sociodemographics population, clinical and obstetrics characteristics, and prepregnancy BMI.

The average weight gain was $13.08 \pm 6.08$. Regarding the adequacy of weight gain per BMI categories, $55.9 \%$ of women with overweight and $53.7 \%$ of obese women gained excessive weight during pregnancy. Most of the pregnant 


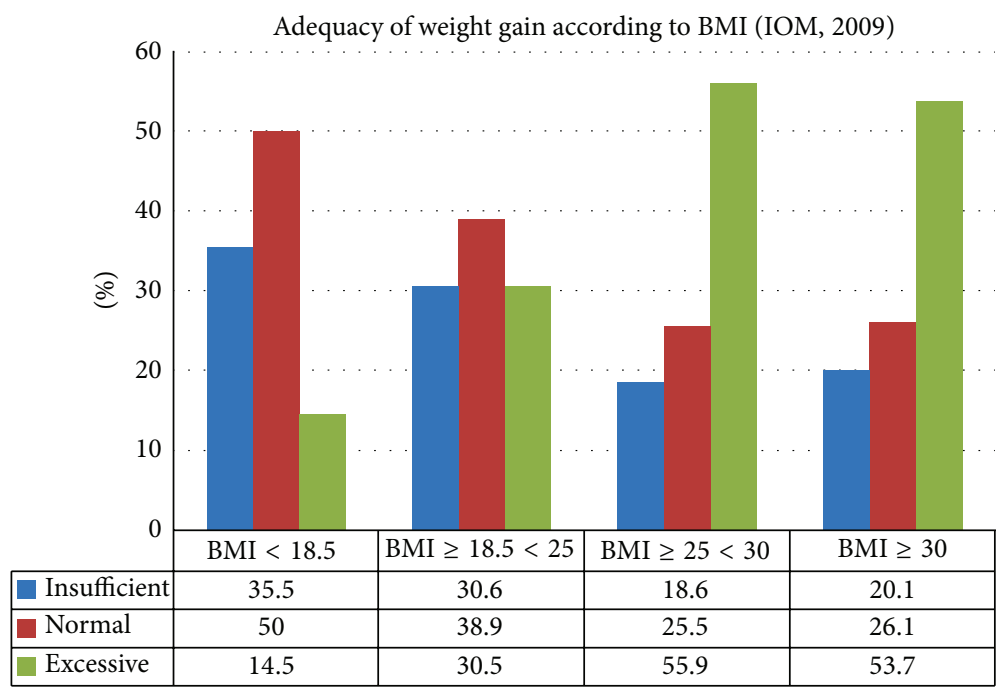

FIGURE 1: Adequacy ranges of weight gain by BMI category according to the recommendations of the Institute of Medicine, 2009, of women in southeast of Brazil. BMI $<18.8 \mathrm{~kg} / \mathrm{m}^{2}$ : between 12.2 and $18 \mathrm{~kg}$; BMI $\geq 18.5<25 \mathrm{~kg} / \mathrm{m}^{2}$ : between 11 and $16 \mathrm{~kg}$; BMI $\geq 25<30 \mathrm{~kg} / \mathrm{m}^{2}$ : between 7 and $11.5 \mathrm{~kg} ; \mathrm{BMI} \geq 30 \mathrm{~kg} / \mathrm{m}^{2}$ : between 5 and $9 \mathrm{~kg}(\mathrm{IOM}, 2009)$.

TABLE 2: Weight gain and risk of excessive weight gain according to BMI category (IOM, 2009) of women in southeast of Brazil.

\begin{tabular}{|c|c|c|c|c|c|c|}
\hline BMI & Mean WG & $P$ value** & WG excessive (\%) & OR & CI 95\% & $P^{*}$ \\
\hline Total sample & $13.08 \pm 6.08$ & & & & & \\
\hline $\mathrm{BMI}<18.5$ & $13.70 \pm 4.25$ & $<0.0001$ & 14.5 & 0.37 & $0.17-0.80$ & 0.009 \\
\hline $\mathrm{BMI} \geq 18.5<25$ & $13.69 \pm 5.21$ & & 30.5 & Reference & - & - \\
\hline $\mathrm{BMI} \geq 25<30$ & $12.38 \pm 6.29$ & & 55.9 & 2.7 & $1.05-4.01$ & $<0.0001$ \\
\hline $\mathrm{BMI} \geq 30$ & $9.57 \pm 8.10$ & & 53.7 & 2.62 & $1.67-4.12$ & $<0.0001$ \\
\hline
\end{tabular}

${ }^{*}$ Chi-square; ${ }^{* *}$ Kruskal-Wallis for mean of weight gain among BMI categories, OR: odds ratio; CI: confidence interval; WG: weight gain.

women with lower BMI presented adequate weight gain; however they had a higher rate $(35.5 \%)$ of insufficient weight gain. It is important to highlight that those women with adequate prepregnancy BMI showed an equal distribution according to different levels of weight gain during pregnancy (Figure 1). Frequency of hypertension and diabetes was 3.3\% and $5 \%$ for women with lower weight, respectively, $36.67 \%$ and $20 \%$ for eutrophic women, $12.5 \%$ and $36.6 \%$ for women with overweight, and $34.4 \%$ and $38.3 \%$ for obese women.

The overweight and obese pregnant women showed higher risk to weight gain during pregnancy; otherwise women that started the prenatal care with lower weight had lower risk to an excessive weight gain (Table 2).

The rate of prematurity was higher in obese pregnant women as well as in the underweight pregnant women. However, the newborn weight was correlated to prepregnancy maternal BMI and the newborn weight increases according to maternal weight. Overweight and obese women showed newborns with higher weight at birth (4.5\% and 6.9\%); on the other hand underweight women showed newborns with $<2500 \mathrm{~g}$. The rate of $\mathrm{c}$-section in this population was $58.9 \%$ and increases according to GWG (Table 3).

According to their prepregnancy BMI, women with excessive weight gain and obese women had higher chance to have LGA newborn (Table 4).

\section{Discussion}

This study has shown that, in Campinas, Brazil, the excessive gestational weight gain rate was higher among those women who were overweight (55.9\%) and obese (53.7\%).

In the USA, more than a quarter of women are overweight and one-third are obese [21]. In a study with Australian women, $47.8 \%$ were overweight or obese and $40 \%$ of those with overweight and $64 \%$ of those with obesity exceeded weight gain during their gestational period [22]. In Brazil, similar results were found in the study done in the northeast; $45.5 \%$ of pregnant women exceeded weight gain during gestational period [23]. When it is compared to other countries, the excessive weight gain rate is similar to Brazil. In a study done in Pittsburgh, USA, 47\% of women put on weight excessively during pregnancy; among those women with pregestational overweight $26 \%$ and $14 \%$ of those with obesity put on weight excessively during pregnancy [24].

The high inadequate weight gain percentage during gestational period $35.5 \%$ of low weight had insufficient gain and $55.9 \%$ and $53.7 \%$ among women with overweight and obesity, resp., put on weight excessively) was pretty much similar to those found in study done with 204 pregnant women where $45.5 \%$ of those exceeded the gain [23]. 
TABLE 3: Pregnancy outcomes according to BMI category of women in southeast of Brazil.

\begin{tabular}{|c|c|c|c|c|c|c|}
\hline Gestational outcomes & Total sample & $\mathrm{BMI}<18.5$ & $\mathrm{BMI} \geq 18.5<25$ & $\mathrm{BMI} \geq 25<30$ & $\mathrm{BMI} \geq 30$ & $P$ value \\
\hline Final weight $(\mathrm{kg})-$ mean \pm SD & $77.39 \pm 14.13$ & $60.19 \pm 6.40$ & $71.46 \pm 8.21$ & $83.12 \pm 9.61$ & $99.54 \pm 13.8344$ & $<0.0001^{* *}$ \\
\hline C-section rate- $n(\%)$ & $619(58.9)$ & $31(49.21)$ & $318(55.99)$ & $159(63.35)$ & $101(72.66)$ & $<0.0001^{*}$ \\
\hline $\begin{array}{l}\text { Gestational age at } \\
\text { birth-weeks-mean } \pm \text { SD }\end{array}$ & $38.10 \pm 1.38$ & $38.54 \pm 1.59$ & $38.76 \pm 1.47$ & $38.85 \pm 1.42$ & $38.43 \pm 1.81$ & $0.1183^{* *}$ \\
\hline Prematurity rate $<37$ weeks $-n(\%)$ & $58(5.9)$ & $4(6.67)$ & $30(5.55)$ & $9(3.70)$ & $10(8.20)$ & $0.0498^{*}$ \\
\hline Newborn weight $(g)-$ mean \pm SD & $3298.12 \pm 454.96$ & $3071.87 \pm 414.99$ & $3217.57 \pm 441.86$ & $3303.10 \pm 442.00$ & $3306.66 \pm 539.03$ & $0.0003^{* *}$ \\
\hline \multicolumn{7}{|l|}{ Newborn weight $(\mathrm{g})-n(\%)$} \\
\hline$<2500$ & $59(5.8)$ & $6(9.68)$ & $34(6.10)$ & $9(3.70)$ & $9(6.98)$ & $<0.0001^{*}$ \\
\hline $2500-3999$ & $923(90.7)$ & $56(90.32)$ & $507(91.02)$ & $223(91.77)$ & $111(86.05)$ & \\
\hline$\geq 4000$ & $36(3.5)$ & - & $16(2.87)$ & $11(4.53)$ & $9(6.98)$ & \\
\hline
\end{tabular}

${ }^{*}$ Chi-square; ${ }^{* *}$ Kruskal-Wallis; SD: standard deviation; BMI: body mass index.

TABLE 4: Association between excessive weight gain and LGA and between prepregnancy BMI and LGA of women in southeast of Brazil.

\begin{tabular}{lcc}
\hline & LGA-n (\%) & OR $(\mathrm{CI} 95 \%)$ \\
\hline Adequacy of weight gain & & \\
Excessive weight gain & $21(5.7 \%)$ & $2.83(1.19-6.76)$ \\
Insufficient weight gain & $4(1.6 \%)$ & $0.75(0.22-2.58)$ \\
Adequate weight gain & $7(2.1 \%)$ & Reference \\
Prepregnancy BMI & & - \\
BMI $<18.5$ & $15(2.7 \%)$ & Reference \\
BMI $\geq 18.5<25$ & $10(4.3 \%)$ & $1.58(0.70-3.56)$ \\
BMI $\geq 25<30$ & $9(7.2 \%)$ & $2.75(1.18-6.44)$ \\
BMI $\geq 30$ &
\end{tabular}

${ }^{*}$ Complete data of 992 cases; OR: odds ratio; CI: confidence interval; BMI: body mass index; LGA: large for gestational age.

The level of education is a factor that may be associated with gestational weight gain, reflecting the socioeconomic status of women, because women with lower purchasing power consume more high-calorie food because of its low cost, leading to excess weight gain in pregnancy. In Brazil two studies conducted in southeast and in northeast showed that $46 \%$ and $51.8 \%$ of women, respectively, had completed more than eight years studied, corresponding to more than grade school $[23,25,26]$. In our study, $58.8 \%$ of women had completed high school, followed by $20 \%$ of women who had a degree.

Among those women interviewed in this study $56.2 \%$ worked during pregnancy, and according to another study conducted in Brazil, 45\% of women had job/occupation outside their home [27]. When compared to other countries, Brazil is below the level of occupation in women who had pregnancy; in a study conducted in China $77.6 \%$ of women worked outside their home [28].

The relation between multiparity and excessive weight gain in pregnancy is discussed in which $47.4 \%$ of women were primiparous. In a study conducted in São Paulo, the authors observed similar data, where $46.2 \%$ of women in the sample were primigravidae [25].

Adequate prenatal care should rely on monitoring all stages of pregnancy, such as interventions and counseling about the various phases and complications that pregnancy can cause. However, the quality of prenatal is difficult to measure and evaluate, especially when it is not the central purpose of the study. In this population the average gestational age at initiation of prenatal care was $12.03 \pm 5$; gestational weeks were considered appropriate to begin prenatal appointments.

These data are suitable for those recommended by WHO, which suggests that the first visits should be held between eight and 12 weeks of gestation and the minimum number of visits is at least four times, and in this study the average number of visits was $8.78 \pm 2.24$ [29].

In a study conducted in four basic healthcare facilities in the state of Rio de Janeiro, Brazil, it was found that despite the fact that $98.8 \%$ of pregnant women received prenatal care, they had high rates of excessive gestational weight gain during pregnancy (39.5) [26]. Smoking was not a prevalent practice and so in a study conducted with 1678 women in Rio de Janeiro only $12 \%$ smoked during pregnancy [30]. In a Chinese study $5.3 \%$ of pregnant women who were smokers did not smoke during pregnancy [28].

c-section prevalence was $58.9 \%$ in the study population, far from the ideal rate which is $15 \%$ recommended by the World Health Organization (WHO). In a survey conducted by WHO in 2009, with the countries of Latin America, Brazil took the last position in the practice of c-section, where the country that had the highest rate was Paraguay [31]. However, high rates of c-sections in Brazil represent a national problem 
and growing health concern, especially when associated with overweight or obesity.

A meta-analysis of 33 studies found that the risk of csection increases proportionally with the increase of BMI (overweight and obesity) [32]. A study conducted in Brazil with 1117 women showed a direct relation to prepregnancy $\mathrm{BMI}$ and weight gain during pregnancy, where overweight and obese women present a greater risk of c-section delivery [1]. In the United States (Pittsburgh) in a study of 477 women, the rate of c-section was 16\% (77 women), and the rate of c-section delivery in women who exceeded the weight gain during pregnancy was 19\% (42 women) [24].

This study aimed to describe the gestational weight gain and the characteristics of pregnant women who went to the major maternity hospitals in southeast of Brazil and identify risks associated with prenatal. The main finding of this study was the high rate of overweight and obese BMI pregnancy and exceed GWG in these groups. Both overweight and obesity are considered problems not only in the Brazilian population but also in different regions of the world; it represented a worldwide problem in the obstetric population. Lack of knowledge about the limits of weight gain during pregnancy is limiting factor for women to achieve appropriate weight gain during this phase [22].

Pregnancy is a phase of women's life where they need special health care and so studies show that strategies to promote public health are important to provide changes in lifestyle, mothers diet adjustment, and physical exercises during the prenatal, in an attempt to adjust the weight gain during pregnancy and prevent obstetric risks and retention of postpartum weight, thus improving women's health in the long term [33-37].

\section{Conflict of Interests}

The authors declare that there is no conflict of interests regarding the publication of this paper.

\section{References}

[1] C. V. Gonçalves, R. A. Sassi-Mendonça, J. A. Cesar et al., "Índice de massa corporal e ganho de peso gestacional como fatores preditores de complicações e do desfecho da gravidez," Revista Brasileira de Ginecologia e Obstetrícia, vol. 34, no. 7, pp. 304-309, 2012.

[2] "World Health Organization," http://www.who.int/mediacentre/ factsheets/fs311/en/.

[3] Ministério da Saúde, "Vigitel 2012: Vigilância de Fatores de Risco e Proteção para Doenças Crônicas por Inquérito Telefônico," http://portalsaude.saude.gov.br/portalsaude/arquivos/ pdf/2013/Ago/27/coletiva_vigitel_270813.pdf.

[4] S. Thangaratinam, R. Rogozinska, K. Jolly et al., "Interventions to reduce or prevent obesity in pregnant women: a systematic review," Health Technology Assessment, vol. 16, no. 31, 2012.

[5] P. L. Assunção, A. S. O. Melo, M. M. R. Amorim et al., "Ganho de peso gestacional: determinantes e suas repercussões clínicas e perinatais," Femina, vol. 31, no. 4, pp. 218-222, 2009.

[6] S. L. Nascimento, F. G. C. Surita, M. A. Parpinelli et al., "Exercício físico no ganho de peso e resultados perinatais em gestantes com sobrepeso e obesidade: uma revisão sistemática de ensaios clínicos," Cadernos de Saúde Pública, vol. 27, no. 3, pp. 407-416, 2011.

[7] M. J, Brown, M. Sinclair, D. Liddle et al., "A systematic review investigating healthy lifestyle interventions incorporating goal setting strategies for preventing excess gestational weight gain," PLoS ONE, vol. 70039503, 2012.

[8] "Perinatal Mortality 2007: United Kingdom," Confidential Enquiry Into Maternal and Child Health, CEMACH, London, UK, 2009.

[9] S. J. Herring, D. B. Nelson, A. Davey et al., "Determinants of excessive gestational weight gain in Urban, low-income women," Women's Health Issues, vol. 22, no. 5, pp. e439-e446, 2012.

[10] I. Guelinckx, R. Devlieger, K. Beckers, and G. Vansant, "Maternal obesity: pregnancy complications, gestational weight gain and nutrition," Obesity Reviews, vol. 9, no. 2, pp. 140-150, 2008.

[11] D. J. Rouse and F. S. Nuthalapaty, "The impact of obesity on fertility and pregnancy," UpToDate, 2007, http://www.uptodate.com.

[12] R. Li, S. Jewell, and L. Grummer-Strawn, "Maternal obesity and breast-feeding practices," The American Journal of Clinical Nutrition, vol. 77, no. 4, pp. 931-936, 2003.

[13] E. Baracho, S. M. Baracho, and L. Almeida, "Adapatoções do sistema músculoesquelético e sua implicações," in Fisioterapia Aplicada à obstetrícia, uroginecologia e aspectos de mastologia, E. Baracho, Ed., pp. 34-41, Guanabara Koogan, Rio de Janeiro, Brazil, 4th edition, 2007.

[14] I. M. Mogren and A. I. Pohjanen, "Low back pain and pelvic pain during pregnancy: prevalence and risk factors," Spine, vol. 30, no. 8, pp. 983-991, 2005.

[15] Y. D. 'Arcy, "Pain and Obesity," Nursing Management, 2012, http://www.nursingcenter.com/lnc/cearticle?tid=1312850.

[16] B. A. Polley, R. R. Wing, and C. J. Sims, "Randomized controlled trial to prevent excessive weight gain in pregnant women," International Journal of Obesity, vol. 26, no. 11, pp. 1494-1502, 2002.

[17] V. K. Knudsen, B. L. Heitmann, T. I. Halldorsson et al., "Maternal dietary glycaemic load during pregnancy and gestational weight gain, birth weight and postpartum weight retention: a study within the Danish National Birth Cohort," British Journal of Nutrition, vol. 109, no. 8, pp. 1471-1478, 2013.

[18] E. Buschur and K. Catherine, "Guidelines and interventions for obesity during pregnancy," International Journal of Gynaecology and Obstetrics, vol. 119, no. 1, pp. 6-10, 2012.

[19] Institute of Medicine (IOM), Subcommitee on Nutritional Status and Weight Gain During Pregnancy, Institute of Medicine, Nutrition During Pregnancy, National Academies Press, Washington, DC, USA, 1990.

[20] G. R. Alexander, J. H. Himes, R. B. Kaufman et al., "A United States National reference for fetal growth," Obstetrics and Gynecology, vol. 87, no. 2, pp. 163-168, 1996.

[21] "Challenges for the overweight and obese urban women," Committee Opinion, The American College of Obstetricians and Gynecologists 470, 2010.

[22] A. Shub, E. Y. S. Huning, K. J. Campbell et al., "Pregnant women's knowledge of weight, weight gain, complications of obesity and weight management strategies in pregnancy," $B M C$ Research Notes, vol. 6, no. 278, pp. 2-6, 2013.

[23] E. M. F. Santos, L. P. Amorim, O. L. N. Costa et al., "Perfil de risco gestacional e metabólico no serviço de pré-natal de 
maternidade pública do Nordeste do Brasil," Revista Brasileira de Ginecologia e Obstetrícia, vol. 34, no. 3, pp. 102-106, 2012.

[24] C. K. McClure, J. M. Catov, R. Ness et al., "Association between gestational weight gains and BMI abdominal adiposity, and traditional measures of cardiometabolic risk in mothers $8 \mathrm{y}$ postpartum," The American Journal of Clinical Nutrition, vol. 98, pp. 1218-1225, 2003.

[25] S. C. Konno, M. H. D. Benicio, and A. J. D. Barros, "Factors associated to the evolution of gestational weight of pregnant women: a multilevel analysis," Revista de Saúde Pública, vol. 41, no. 6, pp. 995-1002, 2007.

[26] T. A. Fernandes, G. L. Werneck, and M. H. Hasselmann, "Prepregnancy weight, weight gain during pregnancy, and exclusive breastfeeding in the first month of life in Rio de Janeiro, Brazil," Journal of Human Lactation, vol. 28, no. 1, pp. 55-61, 2012.

[27] L. M. Andreto, A. I. Souza, J. N. Figueiroa et al., "Fatores associados ao ganho ponderal excessivo em gestantes atendidas em um serviço público de pré-natal na cidade de Recife, Pernambuco, Brasil," Cadernos de Saúde Pública, vol. 22, no. 11, pp. 2401-2409, 2006.

[28] N. Li, E. Liu, J. Gou et al., "Maternal prepregnancy body mass index and gestational weight gain on offspring overweight in early infancy," PLoS ONE, vol. 8, no. 10, Article ID 007780, 2013.

[29] World Health Organization, Antenatal Care in Developing Countries: Promises, Achievements and Missed Opportunities: An Analysis of Trend, Levels and Differentials, WHO Library Cataloguing in Publication Data, 2003.

[30] D. Marano, S. G. N. Gama, A. P. E. Pereira et al., "Adequação do ganho ponderal de gestantes em dois municípios do Estado do Rio de Janeiro (RJ), Brasil, 2008," Revista Brasileira de Ginecologia e Obstetrícia, vol. 34, no. 8, pp. 386-393, 2012.

[31] World Health Organization, Rising Caesarean Deliveries in Latin America: How Best to monitor Rates and Risks Policy Brief, Department of Reproductive Health and Research and Special Programme of Research, Development and Research Training in Human Reproduction, 2009.

[32] S. Y. Chu, S. Y. Kim, C. H. Schmid et al., "Maternal obesity and risk of cesarean delivery: a meta-analysis," Obesity Reviews, vol. 8, no. 5, pp. 385-394, 2007.

[33] S. E. Atalah, C. L. Castilho, and R. R. Castro, "Propuesta de um nuevo estandar de evaluación nutricional en embarazadas," Revista Médica de Chile, vol. 125, pp. 1429-1436, 1997.

[34] B. A. Polley, R. R. Wing, and C. J. Sims, "Randomized controlled trial to prevent excessive weight gain in pregnant women," International Journal of Obesity, vol. 26, no. 11, pp. 1494-1502, 2002.

[35] V. K. Knudsen, B. L. Heitmann, T. I. Halldorsson et al., "Maternal dietary glycaemic load during pregnancy and gestational weight gain, birth weight and postpartum weight retention: a study within the Danish National Birth Cohort," British Journal of Nutrition, vol. 109, no. 8, pp. 1471-1478, 2013.

[36] E. Buschur and K. Catherine, "Guidelines and interventions for obesity during pregnancy," International Journal of Gynaecology and Obstetrics, vol. 119, no. 1, pp. 6-10, 2012.

[37] M. Jeric, D. Roje, N. Medic et al., "Maternal pre-pregnancy underweight and fetal growth in relation to institute of medicine recommendations for gestational weight gain," Early Human Development, vol. 89, no. 5, pp. 277-281, 2013. 

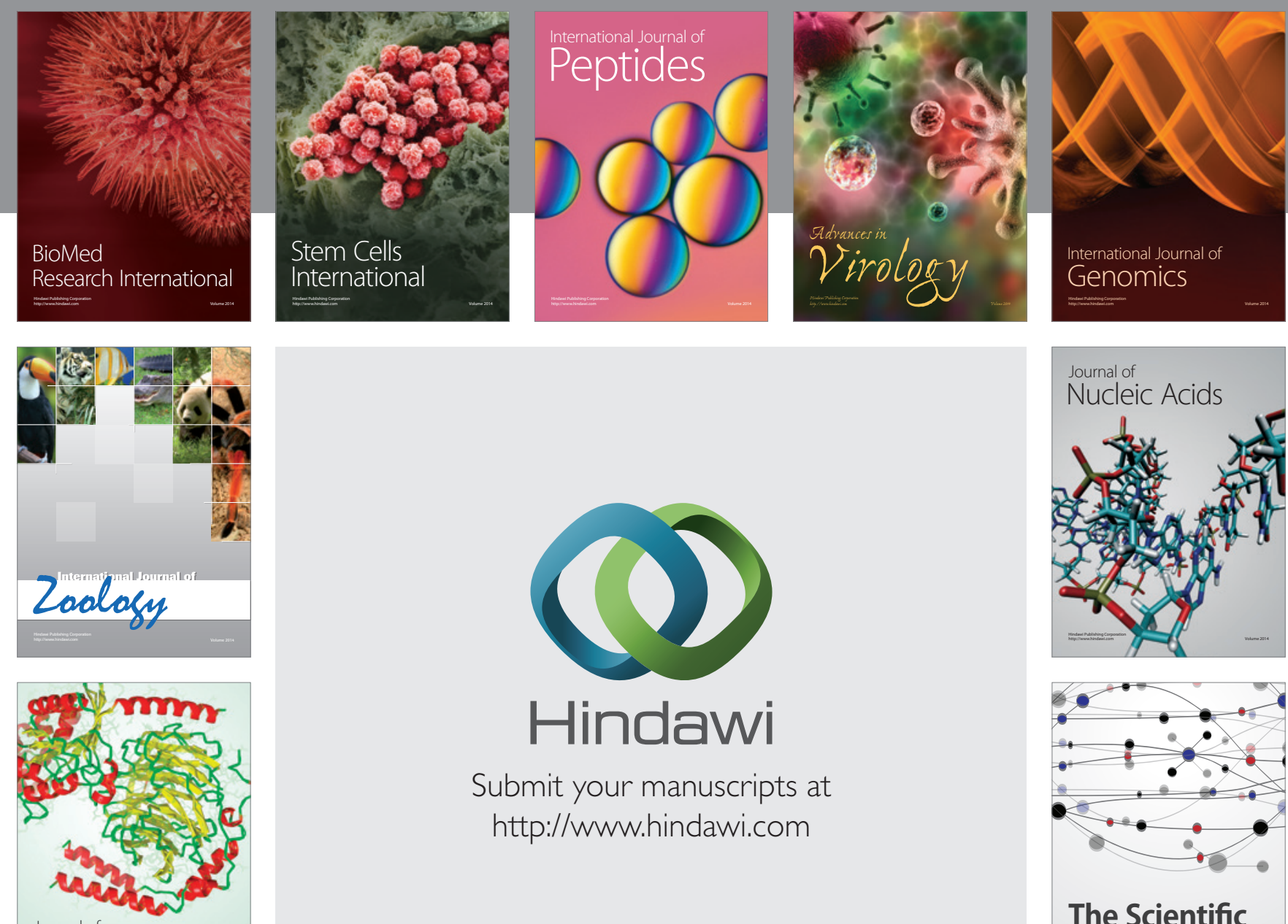

Submit your manuscripts at

http://www.hindawi.com

Journal of
Signal Transduction
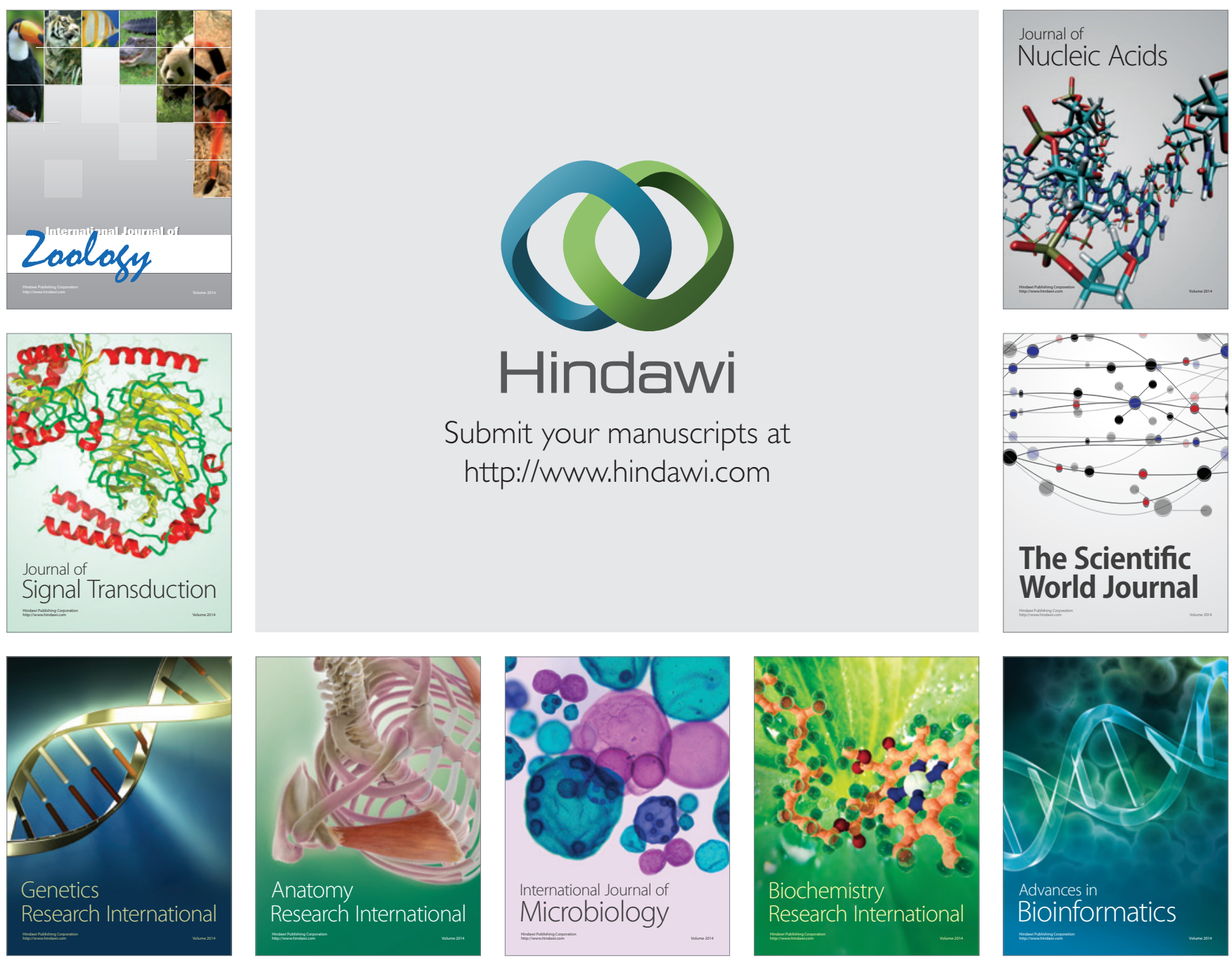

The Scientific World Journal
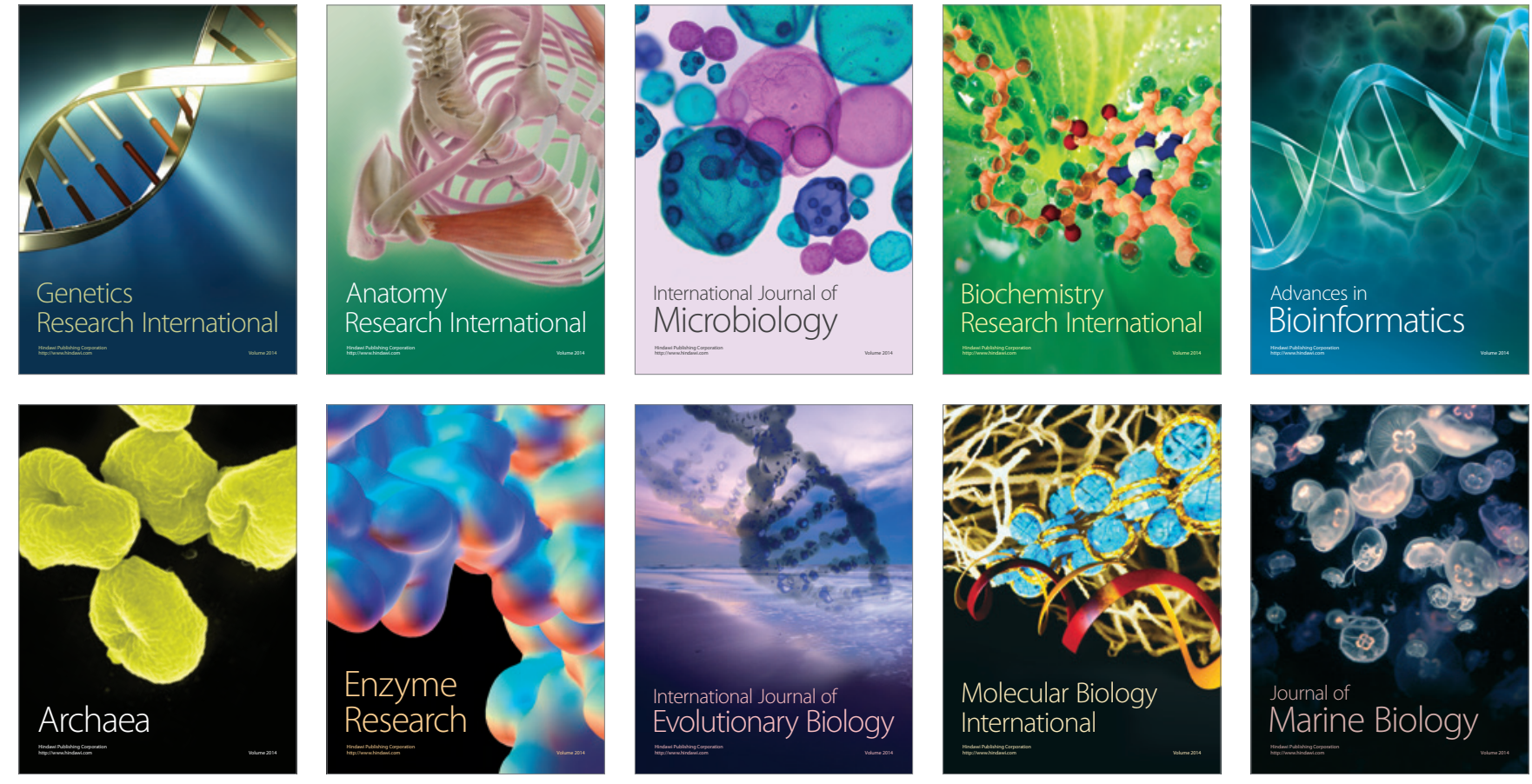